\title{
Privileged Literacies: Policy, Institutional Process and the Life of the IALS
}

\author{
Mary Hamilton \\ Literacy Research Group, Department of Educational Research, Lancaster \\ University
}

This paper argues that in order to make use of the theoretical insights offered by the New Literacy Studies we need to understand more about how institutions produce and privilege certain kinds of knowing - and how, in this process, they devalue or re-define the local and the vernacular for their own purposes. The specific example of the International Adult Literacy Survey (IALS) is used to show how a powerful discourse develops and can organise our knowledge about literacy. The paper presents some theoretical tools that might help us analyse the process whereby this happens. In particular, it explores the potential of Actor-Network Theory (ANT) as an analytical tool. The paper concludes that ANT demonstrates the contingent and precarious way in which social order is created and offers hope that this order can be effectively challenged by alternative projects such as that offered by the NLS.

\section{Introduction}

A central issue for the New Literacy Studies (NLS) is how it can be useful to educational policy and practice. As Puccia and Borman (1998) have pointed out 'organizing an effective presence in policy circles has been achieved by very few anthropologists of education' but this is one of the most important tasks facing the NLS. The argument I make in this paper is that in order to make use of the theoretical insights offered by the NLS we need to understand more about how institutions produce and privilege certain kinds of knowing - and how, in this process, they devalue or re-define the local and the vernacular for their own purposes. To do this, I suggest that we need to focus less on what the teachers and learners are doing (or need to do) and more on what the administrators, testers and government officials are doing with literacy. We should be analysing and debating the dominant public discourses of literacy that inform educational policy and practice. The mass media are central to these, in interaction with government agencies and academic institutions.

In the paper I will develop the specific example of one such discourse offered by the International Adult Literacy Survey (OECD, 1997, 2000). This survey is part of a solidifying international 'regime of truth' which is developing through techniques of standardised assessment and testing and which in turn is organising national and local knowledge about what literacy is (Darville, 1999). I will use the example to present some theoretical tools that might help us analyse how literacies are embedded in the institutional relationships and processes that give them their meaning and how vernacular literacies are defined in relation to these dominant, legitimated practices. In particular I will explore the potential of Actor-Network Theory as an analytical tool, tracing the trajectory 
of the IALS as a social project and focusing on the processes of framing, translation and deletion.

\section{Understanding How Institutional Truths about Literacy are Created}

In the ethnographic research reported in Local Literacies (Barton \& Hamilton, 1998) we argued that while certain literacy practices are supported, controlled and legitimated by powerful institutions others are de-valued. We made the distinction between vernacular (self-generated) and dominant (institutionalised) literacies. This has a parallel with Jim Gee's notion of 'primary' and 'secondary' discourses (Gee, 1990) and the notion of 'the vernacular' was an attempt to characterise the learning that is ignored by formal institutions and where roles/subject positions, goals and procedures are fluid, not necessarily settled or explicitly named.

The vernacular literacies we identified are those that have their origins in the purposes of everyday life but are not regulated, codified or systematised by the explicit rules and procedures of formal social institutions. Whilst many vernacular literacies are influential and valued in people's day-to-day lives, they are also ignored in education. They do not count as 'real' literacy and neither are the informal social networks that sustain these literacies drawn upon or acknowledged. They are not highly valued by formal educational institutions although they exist in dialogic relationship to these institutions.

We defined dominant literacies as those associated with formal organisations, such as the school, the church, the work-place, the legal system, commerce, medical and welfare bureaucracies. They are part of the specialised discourses of bounded communities of practice, and are defined, codified and standardised in terms of the formal purposes of the institution, rather than in terms of the multiple and shifting purposes of individual citizens and their communities. Associated with dominant literacies there are professional experts and teachers through whom access to knowledge is controlled. To the extent that we can group these dominant literacies together, they are given high value, legally and culturally. Dominant literacies are powerful in proportion to the power of the institution that shapes them. This notion is similar to what Bernstein has called 'the official recontextualising field' (see Bernstein, 1996: 48) which will be explained later.

This analysis leads us to ask: What counts as 'real' literacy? How does this notion develop and through what kinds of agency is this decided? How is power exerted through institutions to privilege certain kinds of knowledge and to exclude some others? In order to answer these questions we need to focus on the interconnected institutional systems and environments within which 'knowing' is achieved, to explore how knowing becomes institutionalised and organised resulting in self-evident 'truths'.

Theoretical tools are available for exploring the ways in which institutions exercise and realise power. I now briefly summarise these, looking at the overlaps between them and the special complementary insights that each of them brings to the process I am interested in here. My summary is intended to help make links between theoretical positions that may already be familiar to people working within the NLS. I will suggest that while it is useful to draw on particu- 
lar aspects of the other theories, Actor-Network Theory (ANT) is the most appropriate for the practical task of analysing the life of the International Adult Literacy Suvey (IALS), offering a methodology for tracing it through its creation and dispersion from research contexts to media, policy and educational practice (see Law \& Hassard, 1999). This is a tentative foray into this kind of analysis, but I hope that it will seem fruitful enough to pursue in the future.

\section{Theoretical Tools}

The first theoretical tool comes from Basil Bernstein (1996: 19-21 and 47-8) who offers us the notion of the 're-contextualisation' of knowledge. This explores how knowledge is re-framed within a pedagogical discourse when it is imported into an educational context. Bernstein presents this notion as part of more general processes of the classification and framing of knowledge. 'Classification refers to what, framing is concerned with how meanings are to be put together, the forms by which they are to be made public and the nature of the social relationships that go with this process' (p. 26). In particular, Bernstein identifies a generic mode, the 'official recontextualising field' that is manifest in policy and legislation. This is something like Gee's 'Discourse' with a capital ' $\mathrm{D}$ ' which can be compared with the micro-level discursive interactions that take place day to day as instantiations or contestations of it. Bernstein concerned himself entirely with educational contexts but his theory could usefully be extended to a range of social institutions and their accompanying policy discourses. Certainly we could view the IALS and its surrounding policy discourse as an official re-contextualising field for literacy and explore its relationship with current pedagogical discourses of literacy.

A second useful perspective on institutional power is offered by Etienne Wenger (1998: 57-62) who has written on the characteristics of institutional communities of practice. In particular he presents a model of the collaborative construction of public economies of meaning through the development of communities of practice (designed or emergent) and the notion of 'reification' as an institutional process. He defines reification as 'the process of giving form to our experience by producing objects that congeal this experience into 'thingness'. In so doing, we create points of focus around which the negotiation of meaning becomes organised: 'any community of practice produces abstractions, tools, symbols, stories, terms and concepts that reify something of that practice in a congealed form' (p 58-59). It is clear from the examples of reification given by Wenger that he is sometimes talking about material artefacts and tools, but frequently about forms of representation, including many that involve literacy. Something like a language test would be a powerful form of reification entailing not just a set of understandings about language, but also a set of social relations that are fixed in the processes of test production, administration and participation.

Wenger's work has been applied so far in constrained and well-defined task-oriented organisations such as individual workplaces. His ideas do not transfer so well to interconnected but dispersed networks or chains of activity systems, and they are weak on issues of power and conflict where groups do not share common goals and interests. 
Wenger's notion of reification links with the ideas of Dorothy Smith who points out the central role and especial characteristics of texts as active agents in solidifying and reifying power through what she calls the relations of ruling:

I have come to see the text in its material as well as in its symbolic aspect as the bridge between the everyday/everynight local actualities of our living and the ruling relations. The text is a material object that brings into actual contexts of reading a standardised form of words or images that can be and may be read/seen/heard in many other settings by many others at the same or other times... (Smith, 1999: 7)

It is interesting that these insights have come from theorists who are not centrally concerned with either language or formal education but have arrived at their position about literacy and learning in relation to a broader interest in the social construction of knowledge, the coordination of human activity and the role of institutions in these processes. As we will see later their ideas resonate strongly with the approach of ANT.

Finally, Michel Foucault (1982: 223) whose ideas have shaped the ideas of many subsequent theorists, has identified five institutional 'shaping processes'. These are:

(1) systems of differentiation that define the status of people who have the authority to 'know';

(2) definition of objectives that shape what each person expects to do and how to act in relation to others;

(3) processes that offer incentives for compliance with power relations either through force, economics or surveillance systems;

(4) management structures for decision-making, disseminating information and mobilising resources; and finally

(5) rationalisation, the degree to which these processes are supported and imposed by an all-encompassing technical apparatus.

Foucault has been criticised for his emphasis on the discursive at the expense of the material organisation of the social world, but it is evident from the dimensions identified here that he does point to combinations of discursive, social and material resources in the construction of institutional life and social objects. We can see all of these processes at work in the IALS project and they are also picked up by the approach of ANT, which insists that it is exactly these combinations of material and other resources that should be the focus for explorations of social processes. ANT has the added advantage of proposing a methodology for researching such processes at work. Like Foucault, the approach of ANT focuses on the circulation of power in institutional contexts, on the processes of social life in the making and is anthropological in method.

\section{Actor-Network Theory and Relational Materialism}

Bruno LaTour and John Law offer a perspective from the sociology of science, which Law calls 'relational materialism' and which echoes and draws on the work of LaTour and others, often referred to as ANT. According to Law (1994) relational materialism looks at the resources that are mobilised to establish an 
object of knowledge: people, devices, texts, decisions, organisations and inter-organisational relations. Relational materialism decodes the ordering techniques of those who 'would be powerful and offers a language for telling of the doers' (Law, 1994). At present this perspective has hardly been applied to educational phenomena (except see Pardoe, 2000), but has been used extensively to explore the development and history of scientific innovations.

Relational materialism uses notions of networks and nodes rather than Wenger's notion of 'communities'. It uses an ethnographic approach to trace flows or trajectories of knowledge/social objects in the making: following the chain of events, actors and artefacts, including documents, institutional domains, activities of experts and access to these by 'non-experts'. Like Wenger and Smith, LaTour has pointed out how power accrues through what he calls 'stable mobiles'. These reifications are representations of aspects of the world that are portable and thus can be accumulated and combined in new ways at a distance, and used to coordinate action from within centres of power (see LaTour, 1987: 227ff. and also Law, 1994: 24).

The key to this approach is its emphasis on agency as residing in a combination of human and non-human objects/entities. Key concepts are: translation (the process of making two things that are not the same, equivalent) occurring as a social object circulates through networks on a definable trajectory; the enrolment of agents (human and non-human) into networks as both a tactic and an effect of power; and the principle of general symmetry which insists that all entities, human or non-human must be subjected to the same processes of social analysis; that 'truths' must be subjected to the same process of questioning as 'errors' or deviations.

A network involves a concentration of resources, which typically include physical materials, representations and people. Part of the power of a network is its size and the number and status of agents enrolled to its causes. Entities are produced in relations and agents are network effects, so to understand agency, we have to ask how are the networks assembled? Law (1994: 111) suggests that a project of social ordering generates and embodies characteristic forms of representation (including texts) and that it 'scripts' the performance of those involved. A mode of ordering which survives, becomes stable and powerful, thus defining and performing characteristic ways of speaking or acting. Accordingly, each mode of ordering offers an account of what would count as an ideal speech situation and each tells what would count as interference to that ideal.

Relational Materialism also identifies a set of processes involved in projects of social ordering. First, distribution defines a characteristic approach to what might, does or should pass from whom to what under what circumstances (this links clearly with Foucault's circuits of power in organisations). Entities are defined and generated by the framing of 'the problem'. Problems are framed through projects of social ordering. Framing defines 'what is' on the one hand, and 'what should be' on the other - the gap between these defines the problem and the need for resources to solve it. It defines the strategy and the targets. Part of this framing is the establishment of boundary relations: the limits of this project of ordering in relation to other ones. As previously mentioned, Bernstein (1996) has pointed out the importance of framing to the pedagogical process. Policy-making also entails such problem framing. Further implications of the process of framing are the creation of dualisms (such as literacy/illiteracy). These 
are created by social projects but they become naturalised through processes of institutional reification (cf Wenger). Equally important, certain kinds of entities, activities and practices are deleted or 'silenced' in the process of social ordering.

This is a most promising approach for analysing a complex project like the IALS that relies on the coordinated activity of a range of institutions, their members and traditions and that is still an unstable and ambiguous social object. In fact, whilst the IALS is significant to the NLS because of its impact on educational policy and practice, it can also be viewed as a scientific innovation in its own right, one that is being conspicuously used within a project of social ordering.

In this paper, therefore, I will use relational materialism (or ANT) as a framework to analyse the trajectory of the IALS to date: the flow and concentration of resources within this project. I will focus particularly on the textual representations (the reifications or stable mobiles) that have accumulated as the IALS gathers momentum; and on the processes of translation, framing and deletion that are occurring in this attempt to organise the terrain of literac(ies).

\section{The Example of the IALS: What It Is}

The International Adult Literacy Survey (IALS) is part of a continuing tradition of attempts to measure literacy levels in the adult population by means of surveys and to produce international comparisons. Such research is driven by the search for universals in the relationships between literacy, education and prosperity, which can be used to further the goal of global development. UNESCO began this process of developing international definitions and statistical measures of literacy (see Jones, 1990). The IALS study is organised by the Organisation for Economic Cooperation and Development (OECD), an international governmental body that exists to promote the economic interests of the world's most prosperous countries. The study's findings are now integrated into a set of key statistical indicators to be used by international policy-makers (see OECD/CERI, 1997). It is led by North American academics and governmental researchers employed by the national statistical research agencies in Canada and the USA. The 20 individual national surveys that comprise the IALS to date are financed and carried out by national governments, using national research agencies (such as the Office for NationalStatistics in the UK) and employing academic researchers and methodologies.

The IALS draws on a particular discipline - the psychometric measurement tradition. It uses an information processing model of literacy and attempts to identify levels of literacy skill that are independent of the context of use - the literacy counterpart of the generic and transferable labour skills supposedly possessed by the flexible worker (cf also Bernstein's (1996:56) new performance pedagogies). It creates three dimensions of literacy: prose, document and quantitative. In generating test items, the starting points were texts taken from real-life contexts in a range of countries especially North America. They include bus timetables, advertisements and consumer instructions. These then underwent various transformations to turn them into test items and those showing cultural bias or linguistic translation problems were dropped. The final test rests on 35 texts, each one used as the basis for several question items. The tests are designed to ensure a broad spread of responses across an arbitrarily fixed set of five levels. 
This involves allocating a significant proportion of people to each of the levels, including the lowest. It is important to understand that this distribution is created by the statistical procedures of the IALS and may bear no relation to the distribution of everyday tasks people perform in their lives.

The test items cover commercial, financial, media, advertising and entertainment related texts; work-place, including job-seeking; consumer manuals and instructions; transportation-related and a recipe. In general, the test items require reading and formulaic writing responses (such as form-filling) rather than compositional writing which is difficult to subject to standardised scoring. Not included in the test are religious texts, letters (personal or official), greetings/condolences; legal documents, political, government and policy documents; literature (novels, drama or poetry); historical writing; autobiography; humour and satire. This is, therefore, a very limited, standardised 'generic' view of literacy presented as a universal standard and from which culturally specific material has been partialled out.

The IALS Surveys have been critiqued from a range of perspectives (see Lankshear \& O'Connor, 1999; Levine, 1998; Goldstein, 1998; Graff, 1996; Street 1996; and the response by Jones, 1997). Darville (1999) and Hamilton and Barton (2000) have argued that these surveys fit well within the globalising project of the new capitalism. They are re-defining literacy to fit in with the projected needs of an ideal, consumer-oriented citizen who is responsive to multiple new contexts for literacy use. They justify a vision of what literacy should be, rather than being based on peoples' lived experiences. This is an institutional vision that has little to do with supporting people to use and control literacy for their own purposes. It privileges some literacies and deletes other, vernacular practices and then presents its findings as the 'truth' about literacy.

\section{Analysing IALS as a Project of Social Ordering}

So let us look at how this re-organisation of our knowledge about literacy is being accomplished using the tools provided by Actor Network Theory (ANT). As John Law suggests, I will look first at the creation of the network that supports the IALS. I will identify the resources that have been mobilised in the service of the IALS project: people, devices, texts, decisions, organisations and inter-organisational relations. I will follow the IALS as a new social object looking at how it is stabilised and distributed through the social world via policy, media and advocacy documents. I will comment on the processes of translation, framing and deletion by means of which the IALS loses its origins as it circulates. I will show how the findings become transformed into unquestionable 'facts', how information about procedures, practices and methods and the social relations that produced the findings are lost. This analysis in the words of Richard Darville, is a study of how the IALS 'covers its tracks' (Darville, 1999).

\section{Creating the network: Accumulating and concentrating resources}

According to ANT, part of the power of a network lies in its size and the number and status of actors enrolled in it. The IALS has involved the international mobilisation of a range of heavyweight resources - heavyweight because they draw on high status institutions and experts and large amounts of money. 
The institutions include social research agencies (both universities and others); professional/learned societies; funding agencies; policy agencies, national and international; media; educational institutions responsible for offering literacy programmes. Each of these institutions has its associated experts: these include researchers/interviewers; statisticians; policy-makers at international and national level; journalists and accredited teachers. The IALS achieves a novel combination of these resources.

The international scope and scale of the survey is a major factor in its power, allowing it to claim to represent millions of adults across the world. The introduction to the latest report emphasises that the surveys cover ' 20 countries that between them have more than $50 \%$ of the world's GDP'. The skewed inclusion of the wealthiest countries in the world is thereby promoted as a virtue. An alternative argument might point out that most of the worlds 200 or so countries are not represented at all.

The involvement of national research organisations and experts is a powerful move in terms of legitimising the findings within each country. For example, the National Adult Literacy Agency Journal Sept 1998 carried an information article 'Lessons from the IALS' by one of the authors of the Irish study, Mark Morgan. Morgan argues that it is wrong to refer to the IALS as the 'OECD study of adult literacy'since the studies were carried out by the national research centres of individual countries. This downplays the international role and purpose of the OECD in promoting and coordinating the suite of studies, and emphasises the agency of individual countries and their ownership of the data.

The IALS draws on longstanding research traditions of quantitative, positivistic scientific methodology that are contested within the academic domain, but still command huge respect in media and public domains. These determine the means or mechanisms of ordering, via conventions of research design and report writing; academic dissemination networks; media reporting and policy formulation. The methodologies and procedures entailed by these traditions have generated a wide variety of representations, which serve to reify the IALS project. Some of them are more material in form than others. They include documents describing standards, tests, curricula, reports and statistical tables. These materials as we will see later each have a different provenance: access to some of them is carefully restricted to particular experts whilst others are widely distributed.

The IALS also generates groups of target adults for social policy measures, enumerated and hierarchically ordered by the test results. The test defines and scripts an 'ideal performance' for literacy: $100 \%$ success on the test items. Refusing to take part in the test, performing poorly or denying you have a problem with literacy becomes deviant. The test items themselves come to be regarded as typical literacy activities, regardless of actual everyday literacy practices around those texts or their (ir)relevance to such practices. For example, in the British Daily Telegraph (5 November 1999, p. 7) a key government spokesperson (Baroness Blackstone) is quoted as saying 'We must reform the way basic skills education is provided ... we must drive up demand amongst the seven million adults who have difficulty reading the instructions on a medicine bottle'. A single test item becomes emblematic of the social exclusion of a whole section of the adult population. 
The texts generated from the IALS project vary in their uses, genres and the degree to which they are circulated in the public domain. Some are complex; some are highly simplified as in many media reports and advocacy documents. These documents draw on public discourses and narratives from adjacent policy domains that act to anchor and confirm the truths that are shown by the survey. These discourses are contained in the broad policy statements of the OECD and echoed in national and local policy documentation, and in the media through use of experts. The discourses drawn on include those of economic rationalism and human resource development (training for economic competitiveness); lifelong learning (creating a learning society, with constant renewal of flexible skills); the 'dumbing down' effects of new technologies and popular cultures. These discourses are rife with paradox, exhibiting as they do both anxieties about the decline of traditional print literacies as well as enthusiasm about the possibilities of rapid development of global communications. They are the common currency of public debate.

In the following section I will trace the embedding of the IALS findings into national and finally local pedagogical practice through policy implementation processes, advocacy, teacher-training and curriculum documents. I will trace the trajectory of the IALS by following the trail of documentation that it has generated. I will divide the documents into two sections: creating the test and distributing the findings. I will discuss the original everyday texts, translated for the test; the test itself - booklets containing randomised selections of test items and the stimulus materials; materials used by the interviewers; the test score sheets and interviewer manuals and code books; the statistical findings; the reports (OECD and national governmental); the technical reports; academic commentaries and articles; media coverage; policy and advocacy documents; and curriculum documents.

I will analyse examples, most of them from documents circulated in the UK context, showing the purposes of their use, commenting on the circulation of each, what kind of information about the IALS is included in each, how literacy is framed as a social problem and the translations and deletions that take place in each case.

As a rule of thumb, the more widely distributed a document is, the more simplified the message becomes. There is nothing sinister or conspiratorial in this account. Much of the translation and progressive simplification that happens in the process described here also routinely happens to other research reports. The trajectory is part of the accepted traditions of circulating research data and, as such, this is just one example of a similar fate that can be traced for any number of research studies - not all of them so carefully orchestrated or so loaded with consequence as the IALS. Distribution circuits in the IALS are largely determined at macro level by academic traditions and conventions of public media communication.

\section{Documentary evidence of the trajectory of the IALS: Translations, framing and deletions}

\section{Original everyday texts, translated for the test}

These are not generally accessible outside their countries of origin. They have been lifted from everyday use and practice, recontextualised within the test, 
translated into several languages and 'corrected' for cultural bias. A number of the original items have been dropped from the test as uncorrectable. Here is the first kind of deletion: a selection of test items, and a smoothing out of the original cultural-specific features of the texts. Certain kinds of literate activities, practices and agencies are silenced, as 'culture' is deleted through the search for unbiased test items (Binkley \& Pignal, 1998). Literacy in minority languages in most countries is not visible in the IALS and neither are sub-cultures within national boundaries. In selecting, transforming and recontextualising the everyday texts, decisions are made as to which aspects of literacy are salient to test, and which are not; which aspects of literacy are regarded as vernacular and local, and which are regarded as universal and desirable. Each final item is a consequence of a network of sources, theories, cultural and institutional assumptions, technologies, social practices and institutional procedures. These underpin the test presented to adult respondents.

\section{The test itself - booklets and stimulus materials}

The test that is created from the stimulus items is the core object of the IALS, from which all subsequent texts derive. These documents are closely guarded by the test-makers and national research agencies to ensure that the public do not have access to them and become familiar with them in a way that would jeopardise the validity of the test. Only vetted researchers may see them in a secure and controlled environment - or of course testees, again under highly controlled circumstances. In this way, the test is treated more as a psychological or intelligence test than a vehicle driving test, say, where people are actually encouraged to practice and anticipate the test items in order to show their competence (i.e. literacies treated as propositional knowledge, rather than practice). Agency is invested in the testers and researchers. Testees can only respond in tightly scripted ways (or transgress by not responding) and they have no agency to define what literacy might mean to them. Adults' self-assessments, although recorded, are down graded in relation to the objectivity of the test. As well as defining formats, the testing process defines and enforces the status of experts and non-experts (cf Foucault, 1982). The documents that accompany the test-making, taking and scoring process likewise have a very limited circulation among those employed to design and carry out the research. Interviewer manuals and score sheets are part of the 'tools of the trade'. Testees and members of the public would never see these. They carry crucial information about the minutia of the test-taking and scoring process, decisions about what is included or excluded in categories of response which actually become key to understanding and interpreting the findings (for example, what counts as 'participation in voluntary activities'- see discussion in Hamilton \& Barton, (2000)).

\section{The statistical findings}

The 'raw' findings from the test are largely in the form of numerical data, physically appearing as piles of computer output or tables on the computer screens of national research offices. They reveal correlational patterns of many different kinds but are neutral as to interpretation. They are rarely subjected to causal modeling at least until a later stage. Although already limited by the selection processes and assumptions behind the test that produced them, the figures can 
now be interrogated in a number of ways by researchers. They are not publicly circulated in this form, though they may be archived for future re-analysis.

\section{The reports (OECD and national governmental)}

The surveys are written up as national reports and the findings have also been collated into international comparative reports disseminated from the OECD via government agencies and the media (OECD/Stats Canada, 1995; OECD, 1997; OECD, 2000). These reports are picked up by national and local policy-makers, practitioners and literacy advocates to promote literacy as a social policy issue and to gain funding. In these reports, the statistical findings are carefully presented, with a great deal of attention to accessible writing and visuals; there is an effort to preserve the complexity of the data, which is woven into a highly polished and authoritative interpretative narrative about causation. A persuasive, carefully crafted interpretative framework is woven around the statistics, translating them from raw numbers to explanations. The move from correlation (a co-varying relationship between two variables) to causation (an argument that a change in one variable causes the second to change) is a common one in such research, but is often unwarranted and justified from outside the figures themselves. They contain qualifications to the findings, but gloss over controversy and contradiction. The reports are thick A4 documents, and earlier ones were expensive to buy. The final report is free to all on the web and each report has been released with maximum media publicity.

\section{The technical reports}

Alongside the main reports the technical reports are published. Even thicker and impenetrable in their presentation, these are full of the detail of the research process, explanations of test construction, information about the checks on reliability, validity, reviews of the methodology, sampling errors, translation problems and successes. Here is the nitty-gritty of the research process in action explained in intricate detail. These documents are rarely approached by anyone beyond the interested expert community. They are not designed to be read by those who will go on to report and interpret the IALS report in the media and policy domains, but are presented as if they are mere details for the attention of specialist reader.

Yet within these complex discussions are the keys to the controversies, the caveats, explanations of the limitations and boundaries of the data, the uneven successes of an ambitious and innovative research programme and suggestions for how to develop it in the future. For example, it includes a specially commissioned expert report that concludes that the cross-country comparisons are not valid and should not be presented in the public reports. Kalton et al. (1998:14) recommends that 'no tables ranking countries by literacy level are published'. This advice is then ignored in the main reports, which contain the many comparative tables and bar charts that create the international league table for adult literacy.

Academic commentaries and articles also appear, which deal with the detailed findings, but usually starting from the published results, not the technical material unless the authors are already involved in the research (e.g. Kirsch \& 
Mosenthal, 1990). Here there is informed critique, based on well-articulated academic positions or methodological procedures but rarely circulated or read beyond a narrow academic audience. Subsequent research studies then cite the IALS as a key reference and use it as a starting point for their own investigations (see, for example, Brooks et al., 2001).

\section{Media reports}

Media coverage varies according to the type of newspaper, whether serious broadsheet, educational or tabloid popular press. The specialist and broadsheet press try to grapple with the detailed findings, though sweeping headlines often sabotages careful reporting. The popular daily press give only very superficial reporting. The IALS is not really front-page 'hard' news but it will be splashed in the serious newspapers so long as it can be fitted into other high profile stories. For example, when the OECD Final Report of the IALS was published, the British national newspaper The Guardian (15 June 2000, p. 3) carried a half-page image plus a report by John Ezard with the headline 'How the British lag behind in reading but lead the world at watching TV' picking up on a link made in the report and also fitting in with a recurrent news narrative about the 'dumbing down' of the population through new technologies. This report includes a comment from 'the OECD official in charge of the report' (Patrick Werquin) offering advice to the prime minister and to TV programme makers to make 'better, more literate $\mathrm{TV}^{\prime}$ '. It is a detailed report that gives many facts and figures from the findings. Other reports link basic skills with skills shortages at work.

At the point of such media coverage some common deletions occur. First, the continuum of literacy (the five levels and the three dimensions used in the IALS tests) and the content of the test disappear to be replaced by 'literacy difficulties' or even 'illiteracy'. The findings are simplified and assimilated to existing understandings of literacy. For example, on 5 November 1999 at the launch of the 'Better Basic Skills' strategy The Sun p.10 reported '16-plus test unveiled for $7 \mathrm{~m}$ adults' who are said to be those 'struggling with the 3Rs'. The Mirror, on the same day reports: '3Rs Test to Fight Adult Illiteracy' and refers to 'Britain's' 7 million illiterate adults' (p.24). There is no direct mention of the IALS survey as the source of these figures but the report goes on to say, 'Ministers are alarmed that Britain is almost bottom of the literacy league in Western Europe with 22 percent of adults struggling to master the basics. Only Poland has a worse record.' The national test shortly to be introduced into the UK is described as containing items that are clearly modelled on the test items used in the IALS.

Secondly, specific reference to the IALS and even the source as a piece of international research disappears, to be replaced by attributions to government agencies or officials/ministers or agentless statements about numbers of adults with problems. The Evening Standard (5 November 1999, p.27) emphasises the compulsory test for long-term jobless adults and finishes a short item with 'A report by Sir Claus Moser, chairman of the Basic Skills Agency, revealed that up to seven million adults in the UK are unable to look up the word 'plumber' in a telephone book. An article in The Daily Telegraph (5 November 1999, p. 7) headed 'Crusade to Help adults who failed at school' quotes the IALS estimates as if they have come directly from government ministers or officials: 'A fifth of the population 
has difficulty following instructions on gym equipment or filling in a passport application, says the Basic Skills Agency' and (no agent at all) 'an estimated 7 million people struggle with daily tasks due to poor skills'.

Finally, any detail about the origins, purposes and methods of the study, anything that would allow questioning of the figures disappears and the findings are presented as naturalised facts. For example in a report headlined 'Back To Basics' The Guardian Further Education Supplement, p. 45, 3 October 2000 Alan Wells gives a trailer for the forthcoming national basic skills strategy. The IALS findings now appear only as 'the estimated 7 million adults with poor literacy and numeracy'. There is no mention any more of a research source for this estimate.

\section{Policy documents}

Depending on the purpose of the policy document, these sometimes keep the subtlety of the IALS definitions and give examples of the kinds of test items that the findings are based on. The big translation that takes place involves the framing of the findings. They are no longer treated as a piece of survey research, but as a policy rationale. Literacy levels (low in relation to other countries) are presented as 'the problem' in relation to desired target levels and the gap in between becomes the space for policy action (just as John Law suggests). We can see this happening very clearly in the translation of IALS to a range of national policy contexts. For example, the countries of the UK and Ireland are at present formulating policy for literacy and lifelong learning. The IALS findings become a bedrock rationale for moving funding into the literacy area, although how this rationale is then elaborated depends on the wider set of social policy goals espoused by each country. In England, exact targets have been set for the next five years and a strategy devised in relation to these. Jim Pateman writing in Literacy Today, (June 2000, p. 20) summarises this strategy:

It's now over a year since the publication of the... Moser Report, which estimated that around seven million adults have poor literacy skills. The report recommended dramatic changes in the adult basic skills service in order to meet the suggested target of halving the problem by 2010. The first phase focuses on improved access and service delivery; the second on building the capacity of the system to respond to greater numbers of learners, and the third phase on driving up demand to bring about a step-change in participation and achievement.

The Basic Skills Agency (2000) in its basic skills strategy for Wales gives very sketchy information about the IALS findings while using them (and other unreferenced - but 'extensive research') to justify a new policy strategy: 'In the next few years we have to... decrease the number of adults with poor basic skills by moving them out of the 1 in 5 group that has difficulties into the 4 in 5 group that broadly doesn't' (Executive Summary, p. 2). The main body of the report carries a little more information, clearly attributed to the IALS, but without any explanation of the basis of the test findings. It includes Wales in a five-country comparison, even though Wales was not sampled as an independent country and a footnote points out that the sample size was small and the figures should be treated with caution. 
The Irish White Paper on Adult Education (Department for Education and Science 2000) uses the IALS carefully to justify its agenda for basic skills (see p. 34, section 1.6.1):

The OECD IALS 1997... focused public attention and urgency on the adult literacy problem in Ireland. On a scale of 1-5 the survey, which was carried out in Ireland in 1995, found that about $25 \%$ of the Irish population scored at the lowest level (Level 1) in the document scale with a further $32 \%$ at Level 2. [explains the meaning of the document scale] The percentage at Level 1 was the highest for any country studied except for Poland.

It then goes on to pick out four correlational findings that fit in with the policy agenda described in the report: high need among older people, among those with lower educational levels, low income and low participation in post-school education and training. Elsewhere in the report the 'problem' thus defined is answered by a commitment to specific funding and targets: ' $£ 73.6 \mathrm{~m}$ is being provided under the National Development Plan to increase investment in this area, with a view to providing services over the lifetime of the plan for some 111,000 adults' (see pp. 15 and 88).

A group of related documents are those written by literacy advocates, practitioner groups or other representatives to press the arguments for new resources for literacy. Although they originate from a different set of people and motivations these documents make very similar use of the IALS findings and often accept the policy framing of the literacy problem as a way of persuading funders and decision- makers. Often these documents quote the IALS findings uncritically, seizing on them as evidence that will work for their cause. For example, the newsletter of a Canadian work-place literacy organisation carries an enthusiastic report on the IALS headlined 'Latest world literacy report a key source' $(A B C$ Canada (24), March 1998). In their rush for resources released by new policy initiatives, these groups do not question the framing of literacy entailed in the IALS, but align themselves with it, thus allowing themselves to be enrolled as further agents to its project.

\section{Curriculum documents}

In this final translation of the IALS project, the findings and the definition of literacy on which they are based become the rationale for organising the pedagogical field, as Bernstein would put it. One of the clearest examples I have so far found of this are in the Ontario Literacy Outcomes framework, where a set of performance indicators are mapped onto the three IALS dimensions of prose, document and quantitative literacy (Ontario Ministry of Education and Training, 1998:17). Once the IALS has arrived in the performance indicators it is a short step from this to the worksheets and teacher discourse of the classroom, completing the re-organisation of learner identity that has already started through the survey process itself and the public circulation of the IALS findings. It is perhaps not surprising that this example should come from Canada where the government support for the survey has been second only to the US.

In England and Wales this final translation step can be seen in a similar mapping of the IALS test levels onto the New Adult Basic Skills curriculum, (although the prose, document and quantitative literacy dimensions are not 
being used in this exercise). In England and Wales there are other competing frameworks for measuring and defining literacy education already active in the adult field, especially a strong drive to extend existing standards from school-based literacy and 'key skills' and home-grown tests developed for other UK based survey research on literacy (see Annex A in Moser, (1999) for a detailed discussion of how these different measures are being mapped onto one another). Other countries, as diverse as Scotland and South Africa, are also considering how the IALS might inform the new curriculum frameworks they are developing. Inevitably, if policy-makers use the IALS estimates of need as a starting point and justification for their actions, then some equivalency has to be maintained between the IALS measures and programme outcomes in order to report on the effectiveness of policy measures.

\section{Discussion}

Surveys such as the (IALS) International Adult Literacy Survey (OECD, 1997) organise our knowledge about literacy and the 'literate subject'. They are based on a particular set of social relations and institutions which have both national and international dimensions and which reside in the domains of government, academia and the media. Such surveys increasingly underpin, model, elaborate and justify educational and policy decisions about funding and pedagogy. They are a prime example of what Gee (2000:191) has identified as 'enactive and recognition work ' and what Law (1994) would call 'projects of social ordering': attempts to get other people to recognise people and things as having certain meanings and values with certain configurations or relationships. These activities continue to be developed with large sums of research money provided by the governments of OECD Countries. They are monitored with interest by other economic groupings such as the European Community, which have parallel agendas in the fields of language testing and translation (e.g. see Office for National Statistics, 2000). The OECD 2000 report states that Japan, Malaysia, Mexico are all experimenting with a similar methodology.

In this paper I have shown how, in the process of circulating the findings of the IALS, they are translated into a simplified, received wisdom about what counts as literacy, who has and has not got it. The origin of this commonsense knowledge becomes obscured; the technical decisions and controversies become invisible within the 'black box' of the IALS (La Tour, 1993). This process closes off questions and the fiction that is IALS, wrapped in the credibility of numbers and the institutional agents enrolled to its cause, becomes accepted as social fact. I have used the concepts developed through the approach of ANT to look in detail at the translations of the IALS findings through this chain of events, actions, texts, particularly tracking how the complexities, caveats, the origins are deleted by this process and lost by the time the findings reach teachers and students of literacy, arriving as part of a reified commonsense truth about literacy.

The story of the IALS is the story of the literacy practices of the powerful (and would-be powerful); it is a story of the workings of institutional power in creating 'truth' and deleting or effectively silencing other, competing versions. One of the striking things about this story is its range across time and space. This is an enterprise that has taken nearly a decade to accomplish; at least 20 countries have 
been involved and the co-ordinated resources of a range of institutional spheres beyond education. The notion of 'community of practice' or even a constellation of such communities does not seem able to do justice to the complexity and power of this particular project of social ordering.

The story told in this paper is an impersonal one, tracked through documents, and not so far fleshed out by the kind of ethnographic detail that has been the hall mark of other studies of relational materialism and of the New Literacy Studies. So this paper defines a research agenda for the future. The research we still need will explore the meetings of international fora and the way literacy surfaces in their agendas (as Philip Jones has done for UNESCO and the World Bank, see Jones, 1990). It will document government-sponsored research organisations and their role in the making of policy about literacy; tell stories about academic tribes, their procedures of evidence-gathering, their alliances and feuds; there will be stories about journalists and the making of news and how literacy surfaces in these agendas. It will tell stories about the policy-making process and the back-room struggles and compromises that produce policy documents (see Walford, 1994). It will uncover the experience of practitioners and the dilemmas and decisions about advocacy in a field where the focus on 'literacy' can be framed in a variety of ways.

Finally we need to have more research into the ways in which this project is enacted at the local level and organises the subjectivities of learners as the IALS ultimately finds its way into the worksheets completed by adult literacy students. These local translations are at one and the same time the most important but the least urgent part of the research agenda I argue for here. We have been sidetracked by its importance and have failed to attend to the other locations where power circulates. This now needs to be redressed if the NLS is to have an impact on policy agendas.

\section{Conclusion}

There are few discourses of literacy that currently have international currency in the public domain. The IALS is one of these and in this paper I have used a version of ANT to show how such discourses accumulate power and thereby marginalise other, more local, discourses of literacy. The account of the life of the IALS to date offers a key example of how institutional truths about literacy are generated, how they can become naturalised as commonsense within educational policy and practice, pushing aside those other truths about literacy known through everyday lived experience of adults and the practitioners who work alongside them.

My aim in de-constructing the networks of power that are establishing the new regime of truth of which the IALS is a part is to enable these other truths to be heard. This will be all the more important as the IALS is extended to other countries in the world with whose cultures it is even more out of sympathy than the existing 20 it claims to represent. Despite its visionary rhetoric the reach of the IALS is, as yet, by no means global. It is still a precarious 'pool of order' (Law, 1994) and it challenges us to develop counter-truths (oppositional discourses) that give voice to the diversity and strength of vernacular literacies.

If, as Law, LaTour, Smith and Wenger all suggest, representations are central 
to institutional ordering and reification, then to effectively counter those orderings and to enter the policy arena we must develop and embed alternative representations. The analysis I have carried out here can direct us to the crucial nodes within the network of institutions/actors, texts and practices that have developed and now sustain current ways of knowing. It can help us recognise projects of social ordering for what they are - power plays by influential networks, rather than scientific truths. And, as Law reminds us, their solidity is highly contingent, their influence can rise and fall:

Concrete walls are solid while they are maintained and patrolled. Texts order only if they are not destroyed en route, and there someone at the other end who will read them and order her conduct accordingly... Agency and size (together with machines, social entities and every other kind of object to which one can point) are uncertain effects generated by a network and its mode of interactions. (Law, 1994: 102-3)

The New Literacy Studies, as a potentially powerful discourse, can offer alternative representations through its articulation of a view of literacy as social practice, its insistence that the technical skills of literacy are indivisible from their contexts of use and the social relations that sustain them. We must keep reminding people that the literacies promoted by dominant policies are not the only literacies and to substantiate this through the detail of convincing ethnographic research. ANT shows the importance of building networks to increase the effectiveness of the NLS - through publication, international meetings, through intervening in public policy debates, by arguing for the validity of the research paradigms within which we work. Above all we need to enrol policy-makers and practitioners to the NLS project, building alliances and working with them to frame literacy in ways that can be turned to practical use. These are the beginnings of a strategy for entering the field of policy and practice.

\section{Correspondence}

Any correspondence should be directed to Mary Hamilton, Literacy Research Group, Department of Educational Research, Lancaster University, Bailrigg, Lancaster LA1 4YL, UK (m.hamilton@lancaster.ac.uk).

\section{References}

Barton, D. (1994) Literacy: An Introduction to the Ecology of Written Language. Oxford: Blackwell.

Barton, D. and Hamilton, M. (1998) Local Literacies: Reading and Writing in One Community. London: Routledge.

Basic Skills Agency (2000) Improving Standards of Literacy and Numeracy in Wales: A National Strategy. London : BSA.

Bernstein, B. (1996) Pedagogy, Symbolic Control and Identity: Theory, Research, Critique. London: Taylor and Francis.

Binkley, M. and Pignal, J. (1998) An analysis of items with different parameters across countries. In S. Murray, I. Kirsch and L. Jenkins (eds) Adult Literacy in OECD Countries: Technical Report on the First International Adult Literacy Survey (pp. 143-60). Washington: US Dept of Education, National Center for Education Statistics (NCES 98-053).

Brooks, G., Harmon, J., Hutchison, D., Kendall, S. and Wilkin, A. (2001) Progress in Adult Literacy. London: Basic Skills Agency. 
Darville, R. (1999) Knowledges of adult literacy: Surveying for competitiveness. International Journal of Educational Development 19, 273-85.

Department for Education and Employment (1999) Better Basic Skills. London: Government Stationery Office.

Department of Education and Science (2000) White Paper on Adult Education: 'Learning For Life'. Dublin: Stationery Office.

Foucault, M. (1982) The subject and power. In H. Dreyfus and P. Rabinow, Michel Foucault: Beyond Structuralism and Hermeneutics. Chicago: University of Chicago Press.

Gee, J. (1990) Social Linguistics and Literacies: Ideology in Discourses. London: Falmer Press.

Gee, J. (2000) The New Literacy studies: from 'socially situated' to the work of the social. In D. Barton, M. Hamilton and R. Ivanic Situated Literacies. London: Routledge.

Goldstein, H. (1998) Models for reality: New approaches to the understanding of educational processes. Professorial Lecture, University of London, Institute of Education.

Graff, H. (1996) The persisting power and costs of the literacy myth. Literacyacross the curriculum 12 (2), 4-5. Montreal: Center for Literacy.

Hamilton, M. and Barton, D. (2000) The International Adult Literacy Survey: What does it really measure? International Journal of Education 46 (5), 377-89. Hamburg: UNESCO.

Jones, P.W. (1990) Unesco and the politics of global literacy. Comparative Education Review $134(1), 41-60$.

Jones, S. (1997) Ending the myth of the 'literacy myth'. Literacy Across the Curriculum 12 (4), 10-17. Montreal: Center for Literacy.

Kalton, G., Lyberg, L. and Rempp, J-M. (1998) Appendix A. Review of methodology. In S. Murray, I. Kirsch and L. Jenkins, Adult Literacy in OECD Countries: Technical Report on the First International Adult Literacy Survey. Washington: US Dept of Education, National Center for Education Statistics (NCES 98-053).

Kirsch, I.S. and Mosenthal, P.B. (1990) Exploring document literacy: Variables underlying the performance of young adults. Reading Research Quarterly 25 (1), 5-30.

Lankshear, C. and O'Connor, P. (1999) Response to adult literacy: The next generation. Educational Researcher 28 (1), 30-36.

Latour, B. (1987) Science in Action. Cambridge, MA: Harvard University Press.

Latour, B. (1993) We Have Never Been Modern. Hemel Hempstead, Harvester Wheatsheaf.

Law, J. (1994) Organizing Modernity. Oxford: Blackwell.

Law, J. and Hassard, J. (1999) Actor Network Theory and After. Oxford: Blackwell.

Levine, K. (1998) Definitional and methodological problems in the cross-national measurement of adult literacy: The case of the IALS. Written Language and Literacy 1 (1), 41-62.

Moser, C. (1999) A Fresh Start:Improving Literacy and Numeracy. Department for Education and Employment.

Murray, S., Kirsch, I. and Jenkins, L. (eds) (1998) Adult Literacy in OECD Countries: Technical Report on the First International Adult Literacy Survey. Washington: US Dept of Education, National Center for Education Statistics (NCES 98-053).

OECD (1997) Literacy Skills for the Knowledge Society. Paris: OECD.

OECD (2000) Literacy in the Information Age. Paris: OECD.

OECD/CERI (1992) Adult Illiteracy and Economic Performance. Paris: OECD.

OECD/CERI (1997) Education Policy Analysis. Paris: OECD.

OECD/Stats Canada (1995) Literacy, Economy and Society: Results of the First International Adult Literacy Survey. Paris: OECD.

Office for National Statistics (2000) Measuring Adult Literacy: The International Adult Literacy Survey in the European Context. London: Office for National Statistics.

Ontario Ministry of Education and Training (1998) Working with Learning Outcomes. Ontario Learning Outcome Framework. Ottawa: Ontario Ministry of Education and Training.

Pardoe, S. (2000) Respect and the pursuit of symmetry in researching literacy and student writing. In D. Barton, M. Hamilton and R. Ivanic (eds) Situated Literacies. London: Routledge.

Puccia, E. and Borman, K. (1998) Book review of Wendy Luttrell's School Smart and 
Mother-Wise: Working Class Women's Identity and Schooling. Anthropologyand Education Quarterly 29 (4).

Smith, D. (1999) Writing the Social: Critique, Theory and Investigation. Toronto: University of Toronto Press.

Street, B. (ed.) (1993) Cross-cultural Approaches to Literacy. Cambridge: Cambridge University Press.

Street, B. (1995) Social Literacies: Critical Approaches to Literacy in Development, Ethnography and Education. London and New York: Longman.

Street, B. (1996) Literacy, economy and society. Literacy Across the Curriculum 12 (3), 8-15. Montreal: Center for Literacy.

Walford, G. (1994) (ed.) Researching the Powerful in Education. London: University College London Press.

Wenger, E. (1998) Communities of Practice: Learning, Meaning and Identities. Cambridge: Cambridge University Press. 